\title{
The relationship of group context and intelligence to the overjustification effect
}

\author{
LINDA L. DeLOACH, KIRK M. GRIFFITH, and RICHARD C. LaBARBA \\ University of South Florida, Tampa, Florida
}

\begin{abstract}
The purpose of this experiment was to examine the effects of group context and intelligence on the overjustification effect in first- and second-grade children. Fifty-two male and female subjects were randomly assigned to reward and control conditions and were tested in groups of three to six. Half the subjects received rewards for completing "connect-the-dot" pictures, and the other half received no reward. Time spent on the task, the number of dots connected, and the number of dots connected per second were recorded as measures of intrinsic motivation for the task. The results obtained indicated that extrinsic rewards had no effect on the children's intrinsic motivation to perform on this task. It was also found that level of assessed intelligence and group context predicted task performance. The results suggest that group interaction may serve to neutralize the reported undermining effect of reward on intrinsic motivation.
\end{abstract}

During the past 25 years, there has been a good bit of theoretical speculation concerning the effects of reward on intrinsic motivation. One of the first systematic evaluations of this effect was reported by Deci (1971). Deci found that the rewarding of college students for the performance of a task in which they were initially interested resulted in a subsequent decrease of interest in the task. This decrease has been called the "overjustification effect" (Lepper \& Greene, 1974). That is, one's intrinsic motivation for an activity may be weakened by inducing the individual to engage in an activity as an explicit means to an external goal. If the goal is psychologically oversufficient in terms of the perceived reward value's being higher than the task justifies, the individual may come to believe that his or her actions are primarily motivated by the reward. In this fashion, intrinsic motivation may decrease.

Deci (1971) explains the overjustification effect in the context of cognitive evaluation theory. He suggests that a shift in the perceived locus of causality, concurrent with a change in the level of intrinsic motivation produced by a reward, results in a decrease in task interest. Subsequently, the reward elicits a different motivational subsystem that establishes an instrumental relationship between the behavior and the reward. Under these conditions, it becomes less likely that the behavior will occur without the reward presentation because of the individual's perception of being extrinsically motivated.

Deci (1981) has elaborated further the overjustification effect by describing two properties of relative

This study is based on a thesis submitted to the Department of Psychology, University of South Florida, in partial fulfillment of the requirements for the MA degree. Reprint requests should be submitted to Linda L. DeLoach, Department of Psychology, University of South Florida, Tampa, Florida 33620. reward salience: a controlling aspect and an informational aspect. If a reward is perceived as providing positive competence information, subsequent intrinsic motivation increases. On the other hand, if a reward is perceived as controlling, a subsequent decrease in intrinsic motivation occurs.

The overjustification effect has not been found to be an inevitable result of the administration of reward. A number of investigators have evaluated some situational variables potentially contributing to the undermining of intrinsic motivation. For example, Lepper, Greene, and Nisbett (1975) found that it is not the reward itself, but rather the expectation of reward, that is responsible for the subsequent loss of interest in a task. Harackiewicz (1979) suggested that performance-contingent rewards have a greater undermining effect on intrinsic motivation than do task-contingent rewards.

A number of other variables have been examined for their potential influence on the overjustification effect. These include initial level of interest in a task (Calder \& Staw, 1975; Daniel \& Esser, 1980), type of reward (Anderson, Manoogian, \& Reznick, 1976; Dollinger \& Thelen, 1978), surveillance (Lepper \& Greene, 1974), and reward salience (Ross, 1976).

Since many school systems employ contingency programs within the classroom to maintain student interest, the use of such programs has become a source of concern to psychologists and educators (Feingold \& Mahoney, 1975). It is conceivable that children who are intrinsically interested in a learning task and who receive a reward for their performance may subsequently lose interest in that task. Prior research efforts in this area have tended to isolate subjects to improve experimental control while examining the overjustification effect. In this study, we attempted to simulate normal classroom situations by studying children in groups and permitting them to interact throughout the experiment. The pur- 
pose of this experiment was to examine the influence of peer presence and of intelligence on the undermining effect of reward on intrinsic motivation.

\section{METHOD}

The subjects were 52 first- and second-grade students from a private Catholic school. Twenty-five males and 27 females were selected from a pool of 65 students whose parents consented to participation in the experiment. Children's ages ranged from 73 to 109 months, with an average age of 90 months. All subjects were administered the Otis-Lennon Mental Abilities Test. The average IQ score for the group was 113 , with a range of 91 to 144. The subjects were divided into groups based on sex and grade, and the groups then were assigned randomly to reward or nonreward conditions. The subjects were tested in groups of three to six.

Forty-five connect-the-dot pictures were given to each of the subjects to complete with multicolored pens. The subjects received groups of 15 pictures over three sessions. The pictures in the three groups were matched for content and number of dots to be connected. A "Good Player Award" certificate and a package of M\&Ms were presented to each subject as a reward. Videotapes of each experimental session were made to facilitate ease and accuracy of scoring.

The subjects were seated in groups of three to six in front of a video camera in a classroom. In Session 1, the subjects were given 15 connect-the-dot pictures, five children's story books, and five different colored Magic Markers. A subject number was pinned to the front of each child's shirt for purposes of identification during scoring. The following instructions were read to the subjects by either a male or a female experimenter:

Does anybody know how to do dot-to-dot pictures? (That's right.) You begin at the number one which is circled on the page and draw a line from it to the number two. Then from number two you draw a line to number three. Then what number do you draw to? That's right! You draw a line from three to four. When you have connected all the dots, you've made a picture like this one. For the next 10 minutes you may draw pictures like the ones I showed you or you may look at the books in front of you. The books have pictures in them and they also tell a story that you can read. You may also do both if you like. While you do this, we are going to take pictures of you so we can better understand how children play. We have some work that we need to talk about, so we won't be able to talk to you while you do this. Go ahead and start and I'll tell you when time is up.

The subjects were given a choice of task to ensure they were intrinsically motivated to perform the task rather than were obeying the experimenters. In order to avoid inadvertent reinforcement of their behavior, there was no experimenter-subject interaction during the sessions. The children were permitted to interact among themselves and could leave their seats if they chose to do so. The experimenters recorded the time each subject spent connecting dots, the number of dots connected, and the number of dots connected per second. These measures constituted a baseline of intrinsic motivation. The subjects who chose to read books were dropped from the study.

In Session 2, the books were removed from the table, and 15 dot-to-dot pictures were placed in front of each subject. Half the subjects were shown the Good Player certificate and told: "This time I am going to give you something for doing the dotto-dot pictures. You will get your name on a certificate that looks like this, and also a package of M\&Ms. Go ahead and draw." The other half of the subjects were simply asked to complete the pictures. This session immediately followed the first. To avoid the confound of subjects' telling other students to expect a reward, the control subjects were run first.
At the end of the second session, each of the subjects in the reward condition received a Good Player certificate with the name of the subject and the experimenter on it. Each subject then placed the certificate on a bulletin board for everyone to see. The subjects then received a package of M\&Ms and were excused for the day. Both symbolic and tangible rewards were used to increase the likelihood of a reinforcing effect's being elicited.

Session 3 was completed the following day at the same time as Session 1. This session was identical to Session 1, except that the rewarded subjects were told that there were no rewards left to give them at the end of the experiment. At the end of the session, the control subjects received a package of M\&Ms for participating in the study.

\section{RESULTS}

Interrater reliabilities for the two independent scorers who recorded time on task from the videotapes in Sessions 1 and 3 were .94 and .89 , respectively. There were no initial differences between the control and experimental groups in IQ score, the number of dots connected, the amount of time spent on the task, and the number of dots connected per second.

The following analyses of covariance were performed to evaluate the amount of variance accounted for in the dependent variable by the independent variables of IQ and reward and their interaction: (1) $\mathrm{T}_{3}=\mathrm{T}_{1}+\mathrm{IQ}+$ $R / N R$, where $T_{3}=$ the number of seconds a subject spent on the task in Session 3, $T_{1}=$ the number of seconds a subject spent on the task in Session 1, IQ = IQ score based on the Otis-Lennon Intelligence Test, and $\mathrm{R} / \mathrm{NR}$ = whether or not a subject was rewarded for task participation ("rewarded" coded as 2 and "no reward" coded as 1); (2) $D_{3}=D_{1}+I Q+R / N R+I Q R$, where $D_{3}$ $=$ the number of dots connected in Session $3, D_{1}=$ the number of dots connected in Session $1, \mathrm{IQ}=\mathrm{IQ}$ score based on the Otis-Lennon Intelligence Test, R/NR = whether or not a subject was rewarded or not ("rewarded" coded as 2 and "no reward" coded as 1 ), and $\mathrm{IQR}=$ the interaction of IQ and the reward/no-reward condition; (3) $\mathrm{DP}_{3}=\mathrm{DP}_{1}+\mathrm{IQ}+\mathrm{R} / \mathrm{NR}$, where $\mathrm{DP}_{3}=$ the number of dots connected per second in Session 3, $\mathrm{DP}_{1}=$ the number of dots connected per second in Session 1, IQ = IQ scored based on the Otis-Lennon Intelligence Test, and $\mathrm{R} / \mathrm{NR}$ = whether or not a subject was rewarded ("rewarded" coded as 2 and "no reward" coded as 1).

Significant $R^{2}$ s were recorded for each analysis of covariance: $\mathrm{R}^{2}=.15, \mathrm{p}<.04$ for $\mathrm{T}_{3}$, Model $1 ; \mathrm{R}^{2}=$ $.40, \mathrm{p}<.001$ for $\mathrm{D}_{3}$, Model 2 ; and $\mathrm{R}^{2}=.18, \mathrm{p}<.02$ for $\mathrm{DP}_{3}$, Model 3.

The IQ variable predicted the majority of the variance in all three analyses of covariance. When the baseline measure in each equation was held constant, and IQ was entered into the analysis last, IQ accounted for $10 \%$ of the variance in Analysis $1(\mathrm{r}=.32, \mathrm{p}<.01), 7 \%$ of the variance in Analysis $2(\mathrm{r}=-.27, \mathrm{p}<.02)$, and $13 \%$ of the variance in Analysis $3(\mathrm{r}=-.36, \mathrm{p}<.0008)$. The reward condition did not contribute significantly to the 
total variance for any of the dependent variables; similarly, the interaction terms did not contribute additional variance.

An analysis of variance revealed that high-IQ subjects (IQ ranges from 115 to 144) spent more time on the task, completed fewer dots, and connected fewer dots per second in Session 3 than in Session 1. Lower IQ subjects (IQ ranges from 91 to 114), however, were consistent in their performance in both sessions. A simple main-effects analysis revealed that the interaction approached statistical significance for IQ and reward in Session $3[F(2,50)=3.88, p<.07]$. This trend indicated that rewarded high-IQ subjects completed fewer dots per second than did nonrewarded high-IQ subjects, whereas lower IQ subjects (regardless of reward condition) completed the most number of dots per second.

An analysis of covariance revealed that when the effects of IQ were covaried out, significant differences among groups were observed for all three dependent variables, within and between reward conditions. These results suggest that it is not the reward that affects children's performance, but rather the information provided by peer behavior within the testing group.

\section{DISCUSSION}

Our intent in this experiment was to determine the influence of group context and intelligence on the overjustification effect in young children. The results of this study suggest that reward administration does not diminish intrinsic motivation under the experimental conditions imposed. In the typical classroom situation, individual work is performed and rewarded in the presence of peers. Previous studies in which reward effects on performance were evaluated under conditions of subject isolation may have removed an important source of variance: that is, the subjects' opportunity to interact with others and the potential influence of social-group context on intrinsic/extrinsic motivation. In this study, access to group interaction during performance on a task superceded any effects of reward on performance. The subjects were found to observe and compare their performance with that of other group members. Evidence for such evaluative sharing among subjects was exhibited in the children's drawings. Subjects within a group not only connected the same number of dots, but also selected the same pictures to complete. These findings suggest to us that the opportunity to gain competence information from peers provides more motivational influence and control than external rewards.

Our results are consistent with those of Boggiano and Ruble (1979), who reported that social comparison that provides direct and unambiguous information about competence level is more effective than reward contingency in maintaining intrinsic motivation in children 9 to 11 years old. These findings suggest that group effects may mitigate the undermining effect of reward on intrinsic motivation, particularly in classroom situations

Level of assessed intelligence also predicted a subject's performance on the dot-to-dot pictures. Children with higher intelligence levels spent more time on the task, but completed fewer dots relative to those with lower IQ levels. This discrepancy may be explained by differential qualitative features of our subjects' drawings. The high-intelligence group used a more varied color selection in their productions, added more detail and shading, and colored their pictures more neatly and fully. The lower intelligence group, on the other hand, tended to simply connect the dots and partially color in their drawings, resulting in less time expended in picture completion. There was a trend for the high-intelligence group that received a reward to spend even more time and to connect fewer dots than did the other groups. It is reasonable to interpret these data in terms of the differential challenge and/or interest elicited by the task. The lower IQ group may have perceived the task as relatively more challenging, leading to a more constant rate of performance across sessions. The high-IQ group, finding the task much less challenging with practice, may have attempted to augment their interest by embellishing and elaborating their productions.

Condry (1977) has reported that the rewarding of subjects who are initially motivated to perform a task may result in slower rates of problem solving. It should be noted in this context that focusing on the rate of production rather than on product quality may result in misleading conclusions about level of intrinsic motivation. Decreased production rates do not necessarily reflect decreased levels of intrinsic motivation.

In summary, we were unable to demonstrate the overjustification effect in first-and second-grade children. Rather, our data point to a neutralizing effect of group interaction on the potentially debilitating effects of reward on performance.

\section{REFERENCES}

Anderson, R., Manoogian, S. T., \& Reznick, J. S. The undermining and enhancing of intrinsic motivation in pre-school children. Journal of Personality and Social Psychology, 1976, 34, 915-922.

Boggiano, A. K., \& Ruble, D. N. Competence and the overjustification effect: A developmental study. Journal of Personality and Social Psychology, 1979, 37, 17-25.

Calder, B. J., \& Staw, B. M. Self-perception of intrinsic and extrinsic motivation. Journal of Personality and Social Psychology, 1975, 31, 599-605.

Condry, J. Enemies of exploration: Self-initiated vs. other-initiated learning. Journal of Personality and Social Psychology, 1977, 35, 459-475.

DANiel, T. L., \& Esser, J. K. Intrinsic motivation as influenced by rewards, task interest, and task structure. Journal of Applied Psychology, 1980, 65, 566-573.

DECI, E. L. Effects of externally mediated rewards on intrinsic motivation. Journal of Personality and Social Psychology, 1971, 18, 105-115.

Deci, E. L. Intrinsic motivation. New York: Plenum Press, 1975.

DECI, E. L. The empirical exploration of intrinsic motivation. In L. Berkowitz (Ed.), Advances in experimental social psychology (Vol. 13). New York: Academic Press, 1981.

Dollinger, S. J., \& Thelen, M. H. Overjustification and children's intrinsic motivation: Comparative effects of four rewards. Journal of Personality and Social Psychology, 1978, 36, 1259-1269.

Feingold, B. D., \& Mahoney, M. J. Reinforcement effects on intrinsic interest: Undermining the overjustification hypothesis. Behavior Therapy, 1975, 6, 367-377.

Harackiewicz, J. M. The effects of reward contingency and performance feedback on intrinsic motivation. Journal of Personality and Social Psychology, 1979, 37, 1352-1363.

LEPPER, M. R., \& GreEne, D. Turning play into work: Effects of adult surveillance and extrinsic rewards on children's intrinsic motivation. Journal of Personality and Social Psychology, 1974, 31, 479-486.

Lepper, M. R., Greene, D., \& Nisbett, R. E. Undermining children's intrinsic interest with extrinsic rewards: A test of the "overjustification" hypothesis. Journal of Personality and Social Psychology, 1975, 28, 129-137.

Ross, M. Salience of reward and intrinsic motivation. Journal of Personality and Social Psychology, 1976, 32, 245-254.

(Manuscript received for publication May 13, 1983.) 